\title{
Thermodynamics of Vinyl Ethers. VIII.* A Study of the Relative Ring Strain Energies and Relative Ring Entropies of Three- to Eight-membered Carbocyclic Rings with One or
} No $s p^{2}$-Hybridized Carbon Atom

\author{
ESKO TASKINEN
}

Department of Chemistry, University of Turku, 20500 Turku 50, Finland

The relative stabilities of three- to eightmembered 1-methoxyvinylcycloalkanes and 1 . methoxyethylidenecycloalkanes have been studied by means of chemical equilibration at several temperatures. The thermodynamic functions of isomerization, in comparison with the corresponding functions for the isomerization of 2-methoxy-3-methyl-1-butene to 2-methoxy3-methyl-2-butene, allowed an estimation of the relative ring strain energies and relative ring entropies of carbocyclic rings with one or no $s p^{2}$.hybridized carbon atom.

Although the values of ring strain energy have been established for a great number of saturated and unsaturated cyclic hydrocarbons (cycloalkanes and cycloalkenes, respectively), relatively few reliable data exist of ring strain energies in carbocyclic hydrocarbons with an $s p^{2}$-hybridized carbon atom in the ring. ${ }^{1-4}$ This is mainly due to a lack of appropriate thermochemical data for such compounds; in fact, in the case of methylenecycloalkanes the standard enthalpy of formation in the ideal gas state at 298.15 $\mathrm{K}$ is known only for methylenecyclobutane.4,5 In addition, the values of $\Delta H_{\mathrm{f}}{ }^{\circ}$ (1, $298.15 \mathrm{~K})$ are known for methylenecyclopentane, ethylidenecyclopentane, and the corresponding cyclohexanes, but no actual enthalpy of vaporization measurements have been reported for these compounds. This lack is not very severe since the standard enthalpy of vaporization can be estimated with good ac-

* Part VII. Acta Chem. Scand. B 28 (1974) 201. curacy from the normal boiling point. ${ }^{6}$ For other cycloalkanes with an exo-cyclic double bond, the enthalpy of formation must be estimated indirectly, which of necessity brings about additional uncertainty in the values of derived quantities, such as ring strain energy. Moreover, there are no gas-phase entropy data for alkylidenecycloalkanes. Gas-phase entropies of many organic compounds can be estimated by the group increment scheme described by Benson et al." but, unfortunately, the values of "ring corrections" for carbocyclic rings with an $s p^{2}$. hybridized carbon atom are not known.

This paper reports the results of an approach to the evaluation of the relative ring strain energies and relative ring entropies of three- to eight-membered carbocyclic rings with one or no $s p^{2}$-hybridized carbon atom. The work is based on the assumption that comparison of the values of the standard enthalpy change, $\Delta H^{\circ}(\mathrm{g}, 298.15 \mathrm{~K})$, and standard entropy change, $\Delta S^{\circ}(\mathrm{g}, 298.15 \mathrm{~K})$, of the reactions (1) and (2) should reflect the changes in ring strain energy and ring entropy on going from the saturated ring to one containing an $s p^{2}$. hybridized carbon atom:

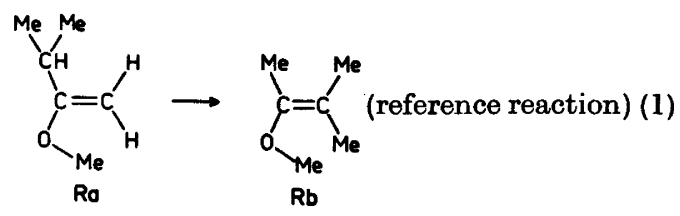

Acta Chem. Scand. B 28 (1974) No. 3 
and, for example,

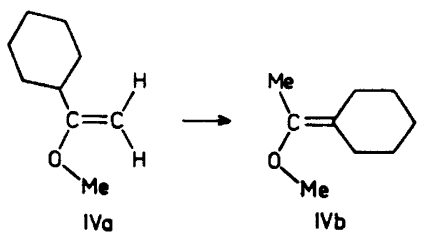

The degree of double bond substitution by alkyl groups undergoes similar changes in each reaction, and as the stabilizing effect of alkyl groups on olefinic double bonds is virtually independent of the alkyl group, ${ }^{8}$ the difference $\Delta H^{\circ}$ (reference reaction) - $\Delta H^{\circ}$ [reaction (2)] should indeed reflect the change in ring strain energy for the six-membered ring on going from IVa to IVb, provided that the effects of steric factors across the double bond are equal in both reactions. This is a critical point, and certain corrections are necessary for small-ring compounds up to cyclopentane.

\section{EXPERIMENTAL}

NMR spectra. The NMR spectra of the vinyl ethers were recorded on a $60 \mathrm{MHz}$ Perkin Elmer R10 spectrometer at $307 \mathrm{~K}$. Carbon tetrachloride was used as solvent and tetramethylsilane as internal standard. In many cases the spectra were recorded from a mixture of isomers containing mainly one of the two isomers and hence the signals due to the protons of the minor component could not always be detected. The spectra are shown in Tables 1 and 2.

Materials. 1-Methoxyvinylcyclopropane (Ia) and its isomer $(I b)$. A mixture of cyclopropyl methyl ketone (0.225 mol, Fluka AG), tri- methylorthoformate $(0.236 \mathrm{~mol})$, and methanol $(0.63 \mathrm{~mol})$ was allowed to stand five days at room temperature in the presence of a small amount of $p$-toluenesulfonic acid, after which the mixture was made alkaline by adding a small volume of sodium methoxide in methanol." Fractionation of the mixture at reduced pressure gave the dimethyl acetal of cyclopropyl methyl ketone (b.p. $312.7-313.2 \mathrm{~K}$ at $3.3 \mathrm{kPa}$ ) in $40 \%$ yield. The acetal was distilled from a small amount of $p$-toluenesulfonic acid at atmospheric pressure to give a mixture of methanol and the desired vinyl ethers, boiling temperature 336$371 \mathrm{~K}$. The mixture was extracted with water to remove the methanol, after which the organic layer was dried over $\mathrm{K}_{2} \mathrm{CO}_{3}$. Distillation from $\mathrm{LiAlH}_{4}$ gave pure Ia (b.p. $377.0 \mathrm{~K}$ at $99.3 \mathrm{kPa}$ ) in $44 \%$ yield.

1-Methoxyvinylcyclobutane (IIa) and its isomer $(I I b)$. The preparation was analogous to that of Ia except that the acetal of cyclobutyl methyl ketone (the ketone was from Ash Stevens Inc., Mich.) was not isolated but the acid reaction mixture was directly subjected to fractional distillation. After a forerun below ca. $380 \mathrm{~K}$, a mixture of IIa and IIb (in the mol ratio of 21 to 1) could be collected at 397.8$398.2 \mathrm{~K}$ at $101.1 \mathrm{kPa}$. The yield was $85 \%$.

1-Methoxyvinylcyclopentane (IIIa) and its isomer (IIIb). 1-Cyclopentylethanol (Aldrich) was oxidized with sodium dichromate in aqueous sulfuric acid to cyclopentyl methyl ketone using the procedure described by Brown and Garg. ${ }^{10}$ The yield of the product boiling at $431.7-432.7 \mathrm{~K}$ at $102.5 \mathrm{kPa}$ was $71 \%$. The ketone was converted to the desired vinyl ethers as described above for IIa and IIb. An approximately equimolar mixture of IIIa and $\mathrm{IIIb}$ was collected at $426-431 \mathrm{~K}$ at $103.3 \mathrm{kPa}$. The yield was $82 \%$.

1-Methoxyvinylcyclohexane (IVa) and its isomer $(I V b)$. The preparation was analogous to that of IIIa and IIIb. The ketone (b.p. $340-341 \mathrm{~K}$ at $1.7 \mathrm{kPa}$ ) was obtained in $79 \%$ yield from 1-cyclohexylethanol (Aldrich). A

Table 1. NMR data for some 1-methoxyvinylcycloalkanes in $\mathrm{CCl}_{4}$ solution. Peak positions are given in $\tau$ values (ppm) and the coupling constant in $\mathrm{Hz}$.

\begin{tabular}{llllll}
\hline Ring size & $\mathrm{H}$ cis to $\mathrm{MeO}$ & $\mathrm{H}$ trans to $\mathrm{MeO}$ & $\mathrm{Me}$ in $\mathrm{MeO}$ & Ring protons & $J\left(=\mathrm{CH}_{2}\right)$ \\
\hline $\mathrm{C}_{3}$ & 6.20 & 6.26 & 6.44 & $\begin{array}{l}8.4-8.9, \\
9.3-9.6\end{array}$ & 2.2 \\
$\mathrm{C}_{4}$ & 6.21 & 6.21 & 6.51 & $6.8-7.4$, & 0.0 \\
$\mathrm{C}_{5}$ & 6.16 & 6.32 & 6.50 & $7.7-8.4$ & \\
$\mathrm{C}_{6}$ & 6.23 & 6.33 & 6.54 & $8.2-8.0$ & 2.0 \\
$\mathrm{C}_{7}$ & 6.20 & 6.37 & 6.53 & $? .8-9.0$ & 2.3 \\
\hline
\end{tabular}

$a$ The spectrum was recorded from a mixture of isomers containing only $30 \%$ of the isomer in question; hence the signals of the major component eclipsed those of the isomer concerned.

Acta Chem. Scand. B 28 (1974) No. 3 
Table 2. NMR data for some 1-methoxyethylidenecycloalkanes in $\mathrm{CCl}_{4}$ solution. Peak positions are in $\tau$ values (ppm).

\begin{tabular}{llll}
\hline Ring size & Me & Me in MeO & Ring protons \\
\hline $\mathrm{C}_{5}$ & $\mathbf{8 . 2 5}$ & 6.56 & $7.6-8.1,8.2-8.6$ \\
$\mathrm{C}_{6}$ & 8.28 & 6.64 & $7.6-8.2,8.3-8.6$ \\
$\mathrm{C}_{7}$ & 8.26 & 6.59 & $7.6-8.1,8.2-8.6$ \\
$\mathrm{C}_{8}$ & 8.26 & 6.58 & $7.6-8.1,8.2-8.6$ \\
\hline
\end{tabular}

$93 \%$ yield of IVa and IVb (in the mol ratio of 4 to 1 ) -was collected at $449-451 \mathrm{~K}$ at 102.1 kPa.

1-Methoxyvinylcycloheptane (Va) and its isomer ( $V b)$. Cycloheptylmagnesium chloride was prepared from cycloheptyl chloride $(0.50$ mol, Aldrich) and magnesium (0.55 mol) in 250 $\mathrm{cm}^{3}$ of dry ether. The Grignard reagent was cooled to ca. $263 \mathrm{~K}$, after which $0.50 \mathrm{~mol}$ of acetaldehyde in $70 \mathrm{~cm}^{3}$ of ether was added to the Grignard reagent during about $0.3 \mathrm{~h}$. The product was allowed to warm to room temperature, after which it was poured on ice. Dilute sulfuric acid was added to dissolve the precipitate. The organic layer was separated, and the aqueous layer was extracted with ether. The combined extracts and the original organic layer were washed with sodium bicarbonate solution and water. After drying over $\mathrm{K}_{2} \mathrm{CO}_{3}$, the ether was evaporated and the residue fractionated to give 1-cycloheptylethanol, b.p. $367-369 \mathrm{~K}$ at $1.3 \mathrm{kPa}$, in $37 \%$ yield. The alcohol was oxidized to cycloheptyl methyl ketone as described above for cyclopentyl methyl ketone. The yield of the product boiling at $355-357 \mathrm{~K}$ at $1.5 \mathrm{kPa}$ was $69 \%$. The ketone was converted into a mixture of $\mathrm{Va}$ and $\mathrm{Vb}$ in the usual manner. The yield was $46 \%$, and the mixture of isomers containing $75 \mathrm{~mol} \%$ of $\mathrm{Vb}$ was collected at $351-353 \mathrm{~K}$ at $1.2 \mathrm{kPa}$.

1-Methoxyvinylcyclooctane (VIa) and its isomer (VIb). Cyclooctanol $(0.34 \mathrm{~mol}$, Fluka AG) was dissolved in chloroform $\left(150 \mathrm{~cm}^{3}\right)$, after which thionyl chloride $(0.39 \mathrm{~mol})$ was added with stirring so that the chloroform refluxed gently. Refluxing was continued for an hour, or until the evolution of gas ceased. The mixture was poured into water, the layers were separated, and the organic layer was washed with saturated sodium bicarbonate solution and water. The product was dried over $\mathrm{MgSO}_{4}$ and distilled to give a $55 \%$ yield of cyclooctyl chloride, b.p. $345.2-346.2 \mathrm{~K}$ at $1.1 \mathrm{kPa}$. 1-Cyclooctylethanol was then prepared from cyclooctylmagnesium chloride and acetaldehyde as described above for 1-cycloheptylethanol. The product, obtained in $15 \%$ yield, was collected at $376-378 \mathrm{~K}$ at $0.9 \mathrm{kPa}$. It was oxidized to cyclooctyl methyl ketone (b.p. $362-364 \mathrm{~K}$ at $0.8 \mathrm{kPa}$ ) in $63 \%$ yield. The ketone was converted into a mixture of VIa and VIb (in the mol ratio of 1 to 20 , respectively) in the usual manner. The product boiled at $358-359 \mathrm{~K}$ at $0.8 \mathrm{kPa}$, and the yield was $62 \%$.

Purification of the vinyl ethers. Prior to the equilibrations, the mixtures of the isomeric vinyl ethers were purified by preparative GLC using a Carbowax 20M column.

Determination of normal boiling points. The normal boiling points of the isomeric vinyl ethers were determined by the gas-chromatographic method described earlier. ${ }^{6}$ The follow. ing compounds were used as the reference compounds (compound, normal boiling point): isobutyl vinyl ether (R1), 356.2 K ; isobutylidene ethyl ether (R2), 366.7 K; 1-methoxycyclopentene (R3), $387.0 \mathrm{~K}$; 1-ethoxycyclopentene (R4), $409.0 \mathrm{~K}$; 1-methoxycyclohexene (R5), 417.1 K; 1-ethoxycyclohexene (R6), $435.0 \mathrm{~K}$; 1-propoxycyclohexene (R7), $455.9 \mathrm{~K}$; 1-cyclopentoxycyclopentene (R8), $479.7 \mathrm{~K}$. The normal boiling points of IIa and IIb were determined by means of the following reference compounds (compound, relative retention time): $R 1,0.255$; R2, 0.286; R3, 0.417; R4, 0.574; R5, 0.708; R8, 1.000. The relative retention times of $\mathrm{IIa}$. and IIb were 0.501 and 0.656 , respectively, corresponding to normal b.p.'s of 399.0 and $413.9 \mathrm{~K}$. III $a$ and $I I I b$, reference compounds and their relative retention times: $R 2,0.149$; $R 3,0.226$; $\mathrm{R} 5,0.411 ; \mathrm{R} 6,0.604 ; \mathrm{R} 7,1.000$. The relative retention times of IIIa and IIIb $(0.461$ and 0.633 , respectively) led to normal b.p.'s of 422.6 and $437.4 \mathrm{~K}$. $I V a$ and $I V b$, reference curve: R2, 0.180; R3, 0.262; R5, 0.440; R6, $0.619 ; \mathrm{R} 7,1.000$. The relative retention times of IVa and IVb (0.817 and 0.971 , respectively) corresponded to normal b.p.'s of 447.5 and $454.6 \mathrm{~K}$. $V a$ and $V b$, reference curve: $\mathrm{R2}, 0.153$; R3, 0.202; R5, 0.303; R6, 0.393; R7, 0.573; R8, 1.000. The relative retention times of $\mathrm{Va}$ and $\mathrm{Vb}(0.844$ and 0.985 , respectively) led to normal b.p.'s of 473.0 and $479.2 \mathrm{~K}$. $V I a$ and $V I b$, reference curve: R2, 0.187; R3, 0.239; R5, $0.341 ; R 6,0.429 ; \mathrm{R} 7,0.604 ; \mathrm{R} 8,1.000$. The relative retention times of VIa and VIb were 1.420 and 1.547 corresponding to normal boiling points of ca. 493.0 and $496.0 \mathrm{~K}$, respectively.

Procedure. Details of the experimental performance of the equilibrations have been described previously. ${ }^{8}$ Iodine was used as catalyst and cyclohexane as solvent. The purities of the vinyl ethers were checked by GLC (Carbowax $20 \mathrm{M}$ and SE-30 columns) and NMR spectra. 
Table 3. Values of the mean equilibrium constant $K$ and its standard error for the iodine-catalyzed reaction 1-methoxyvinylcycloalkane $(a) \rightleftharpoons 1$-methoxyethylidenecycloalkane $(b)$ in cyclohexane solution at various temperatures. The time of equilibration varied from a few days at the lowest temperatures to a few tens of minutes at the highest temperatures employed; $n$ denotes the number of independent determinations.

\begin{tabular}{|c|c|c|c|c|c|c|}
\hline Ring size & $T / K$ & 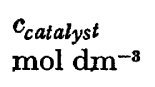 & $\begin{array}{l}c_{\text {substrate }} \\
\mathrm{mol} \mathrm{dm}^{-3}\end{array}$ & $\begin{array}{l}\text { Isomer composition } \\
\text { at start } / \mathrm{mol} \%\end{array}$ & $n$ & $K(\mathrm{~b} / \mathrm{a})$ \\
\hline $\mathrm{C}_{4}$ & $\begin{array}{l}273.2 \\
283.2 \\
299.2 \\
323.2 \\
342.2 \\
373.2 \\
394.2 \\
398.2\end{array}$ & 0.008 & 1.0 & $96(a), \quad 4(b)$ & $\begin{array}{l}\mathbf{3} \\
\mathbf{3} \\
\mathbf{2} \\
\mathbf{3} \\
\mathbf{3} \\
\mathbf{2} \\
\mathbf{3} \\
\mathbf{3}\end{array}$ & $\begin{array}{l}0.0551 \pm 0.0020 \\
0.0667 \pm 0.0015 \\
0.0829 \pm 0.0015 \\
0.1047 \pm 0.0013 \\
0.1284 \pm 0.0009 \\
0.1668 \pm 0.0001 \\
0.1912 \pm 0.0023 \\
0.1989 \pm 0.0001\end{array}$ \\
\hline $\mathrm{C}_{5}$ & \begin{tabular}{l|}
293.2 \\
313.2 \\
323.2 \\
343.2 \\
354.7 \\
366.2 \\
384.2 \\
390.2
\end{tabular} & 0.0008 & 0.3 & $\begin{array}{l}100(a) \\
100(b) \\
100(a) \\
100(b)\end{array}$ & $\begin{array}{l}2 \\
2 \\
2 \\
2 \\
2 \\
2 \\
2 \\
2\end{array}$ & $\begin{array}{l}1.288 \pm 0.001 \\
1.332 \pm 0.002 \\
1.363 \pm 0.002 \\
1.388 \pm 0.005 \\
1.413 \pm 0.007 \\
1.433 \pm 0.002 \\
1.463 \pm 0.008 \\
1.467 \pm 0.001\end{array}$ \\
\hline $\mathrm{C}_{6}$ & \begin{tabular}{l|}
283.2 \\
293.2 \\
298.2 \\
303.2 \\
313.2 \\
323.2 \\
333.2 \\
355.7 \\
375.2 \\
389.7
\end{tabular} & 0.005 & 0.7 & $100(a)$ & $\begin{array}{l}4 \\
7 \\
4 \\
6 \\
9 \\
6 \\
5 \\
2 \\
2 \\
2\end{array}$ & $\begin{array}{l}0.0629 \pm 0.0026 \\
0.0781 \pm 0.0008 \\
0.0818 \pm 0.0009 \\
0.0861 \pm 0.0009 \\
0.1016 \pm 0.0007 \\
0.1177 \pm 0.0010 \\
0.1291 \pm 0.0011 \\
0.1670 \pm 0.0004 \\
0.1997 \pm 0.0007 \\
0.2326 \pm 0.0004\end{array}$ \\
\hline $\mathrm{C}_{7}$ & $\begin{array}{l}283.2 \\
313.2 \\
343.2 \\
373.2 \\
403.2\end{array}$ & 0.008 & 0.6 & $30(a), 70(b)$ & $\begin{array}{l}\mathbf{3} \\
\mathbf{3} \\
\mathbf{2} \\
\mathbf{3} \\
\mathbf{2}\end{array}$ & $\begin{array}{l}2.69 \pm 0.01 \\
2.74 \pm 0.02 \\
2.85 \pm 0.01 \\
2.88 \pm 0.03 \\
2.94 \pm 0.01\end{array}$ \\
\hline $\mathrm{C}_{8}$ & \begin{tabular}{l|}
293.2 \\
313.2 \\
343.2 \\
373.2 \\
402.7
\end{tabular} & 0.008 & 0.5 & $8(a), 92(b)$ & $\begin{array}{l}3 \\
2 \\
2 \\
2 \\
3\end{array}$ & $\begin{array}{l}16.24 \pm 0.27 \\
14.55 \pm 0.07 \\
12.65 \pm 0.04 \\
11.64 \pm 0.08 \\
10.42 \pm 0.04\end{array}$ \\
\hline
\end{tabular}

Peak separation was good, and the compounds were eluted in the sequence a,b. Peak areas, which were considered to be proportional to the molar amounts of the vinyl ethers, ${ }^{\circ}$ were integrated by means of a Hewlett-Packard $3370 \mathrm{~B}$ integrator.

In cases when the synthetic product contained only a small amount of the less stable isomer, the isomers were not separated by preparative GLC, and then only one initial mixture of isomers was used in the equilibrations. To be sure that true equilibrium had been reached, equilibration times were extended well beyond the time necessary for the isomer ratio to become constant. Moreover, the studied compounds are fairly reactive under the experimental conditions employed so that the state of equilibrium is readily attained without noteworthy side-reactions except for the formation of small amounts of hydrolysis products $\left[\mathrm{R}(\mathrm{MeO}) \mathrm{C}=\mathrm{CH}_{2}+\mathrm{H}_{2} \mathrm{O} \rightarrow \mathrm{RCOMe}+\mathrm{MeOH}\right.$; $\left.\mathrm{MeOH}+\mathrm{R}(\mathrm{MeO}) \mathrm{C}=\mathrm{CH}_{2} \rightarrow \mathrm{RMeC}(\mathrm{OMe})_{2}\right]$.

If the less stable isomer could not be separated for its spectral characterization, it was identi- 
fied by its retention time in the gas-chromatographic analyses, and by its behavior in the equilibrations. In no cases did the identification provide any difficulty since in addition to the peaks of the two isomers, the only noteworthy peaks could be shown to be due to the hydrolysis products.

Equilibrium constants could not be determined for the reaction $\mathrm{Ia} \rightleftharpoons \mathrm{Ib}$, since the position of equilibrium lay so far to the left that the peak of Ib could not be detected in the gas chromatogram.

\section{RESULTS}

The values of the mean equilibrium constant $K$ and its standard error at various temperatures are shown in Table 3. As mentioned earlier (see EXPERIMENTAL), equilibrium constants could not be determined for the reaction $\mathrm{Ia} \rightleftharpoons \mathrm{Ib}$ because of the low thermodynamic stability of the $b$ isomer. For each isomerization reaction the standard Gibbs free energy change $\Delta G^{\circ}$, calculated from the mean equilibrium constant, proved to be a linear function of temperature (within experimental error, of course). The values of the standard enthalpy change $\Delta H^{\circ}$ and standard entropy change $\Delta S^{\circ}$ were obtained by a least-squares treatment of $\Delta G^{\circ}$ against temperature $T\left(\Delta G^{\circ}=\Delta H^{\circ}-T \Delta S^{\circ}\right)$. The values of $\Delta G^{\circ}, \Delta H^{\circ}$, and $\Delta S^{\circ}$ in the liquid phase at $298.15 \mathrm{~K}$ are collected in Table 4. The normal boiling points of the isomeric compounds (see EXPERIMENTAL) were then used for the evaluation of the values of the standard enthalpy and standard entropy of vaporization at $298.15 \mathrm{~K} .{ }^{6}$ Table 5 gives the values of $\Delta H^{\circ}$ and $\Delta S^{\circ}$ in the gas phase at $298.15 \mathrm{~K}$. The calculations have been described in more detail in Refs. 6 and 11.

\section{DISCUSSION}

Both molecular models and the available thermochemical data suggest that the compounds studied in this work can be divided into two groups according to the extent of steric cis interactions across the double bond in the $b$ isomer: (i) compounds in which the steric interactions can be assumed to be equal to those in the reference compound $\mathrm{Rb}$, and (ii) compounds in which this is not the case. The latter group includes the three-, four-, and fivemembered compounds, whereas all the other ring compounds belong to the former group. This can be verified by means of thermochemical data as follows.

From available enthalpy of hydrogenation data, ${ }^{12}$ the enthalpy of isomerization of methylenecyclopentane to 1-methylcyclopentene is ca. $-16.2 \mathrm{~kJ} \mathrm{~mol}^{-1}$ in acetic acid at $298.15 \mathrm{~K}$, but the corresponding value for the isomerization of ethylidenecyclopentane to 1-ethylcyclopentene is $-5.4 \mathrm{~kJ} \mathrm{~mol}^{-1}$. The difference in these values shows that the methyl group of ethylidenecyclopentane stabilizes the exo-cyclic double bond by $10.8 \mathrm{~kJ} \mathrm{~mol}^{-1}$, which is practically equal to the hyperconjugative stabilization (11.3 kJ mol-1) in propene, ${ }^{8}$ an apparently "strain-free" molecule. The similarity of these two stabilization energies indicates that there is no measurable destabilization between the methyl group and ring hydrogens of ethylidenecyclopentane. This is supported by the fact that the enthalpy of isomerization of isopropylidenecyclopentane to 1-isopropylcyclopentene is $4.3 \mathrm{~kJ} \mathrm{~mol}^{-1}$ in acetic acid at 298.15 $\mathrm{K},{ }^{13}$ which shows that the second exo-cyclic methyl group in isopropylidenecyclopentane causes an additional stabilization (relative to ethylidenecyclopentan $\theta$ ) of $4.3-(-5.4)=9.7 \mathrm{~kJ}$ $\mathrm{mol}^{-1}$, i.e., not significantly less than the first

Table 4. Thermodynamic data for the reaction 1-methoxyvinylcycloalkane $\rightarrow$ 1-methoxyethylidenecycloalkane in cyclohexane solution at $298.15 \mathrm{~K}$. The errors are twice the standard errors.

\begin{tabular}{lrrr}
\hline Ring size & \multicolumn{1}{c}{$\Delta G^{\circ} / \mathrm{kJ} \mathrm{mol}^{-1}$} & $\Delta H^{\circ} / \mathrm{kJ} \mathrm{mol}^{-1}$ & \multicolumn{1}{c}{$\Delta S^{\circ} / \mathrm{J} \mathrm{K}^{-1} \mathrm{~mol}^{-1}$} \\
\hline $\mathrm{C}_{4}$ & $6.271 \pm 0.046$ & $9.02 \pm 0.26$ & \multicolumn{1}{c}{$9.2 \pm 0.8$} \\
$\mathrm{C}_{8}$ & $-0.654 \pm 0.012$ & $1.27 \pm 0.07$ & $6.46 \pm 0.21$ \\
$\mathrm{C}_{6}$ & $6.211 \pm 0.040$ & $10.98 \pm 0.30$ & $16.0 \pm 0.9$ \\
$\mathrm{C}_{7}$ & $-2.483 \pm 0.023$ & $0.73 \pm 0.13$ & $10.76 \pm 0.38$ \\
$\mathrm{C}_{8}$ & $-6.831 \pm 0.048$ & $-3.89 \pm 0.27$ & $9.9 \pm 0.8$ \\
\hline
\end{tabular}

Acta Chem. Scand. B 28 (1974) No. 3 
Table 5. Thermodynamic data for the reaction l-methoxyvinylcycloalkane $\rightarrow$ l-methoxyethylidenecycloalkane in the gas phase at 298.15 K.

\begin{tabular}{lrc}
\hline Ring size & \multicolumn{1}{c}{$\Delta H^{\circ} / \mathrm{kJ} \mathrm{mol}^{-1}$} & \multicolumn{1}{c}{$\Delta S^{\circ} / \mathrm{J} \mathrm{K}^{-1} \mathrm{~mol}^{-1}$} \\
\hline $\mathrm{C}_{4}$ & $11.42 \pm 0.40$ & $11.9 \pm 0.9$ \\
$\mathrm{C}_{8}$ & $3.66 \pm 0.31$ & $9.0 \pm 0.5$ \\
$\mathrm{C}_{8}$ & $12.12 \pm 0.42$ & $17.1 \pm 1.0$ \\
$\mathrm{C}_{7}$ & $1.73 \pm 0.33$ & $11.7 \pm 0.6$ \\
$\mathrm{C}_{8}$ & $-3.41 \pm 0.40$ & $10.3 \pm 0.9$ \\
\hline
\end{tabular}

methyl group. Hence it appears that in alkylidenecycloalkanes with three-, four-, and fivemembered rings the hydrogen atoms of the exocyclic methyl groups are not capable of interacting with the hydrogen atoms of the ring.

On the other hand, the enthalpy of isomeriza. tion of methylenecyclohexane to l-methylcyclohexene (acetic acid, $298.15 \mathrm{~K}$ ) is only $5.0 \mathrm{~kJ}$ $\mathrm{mol}^{-1}$ more negative than that of ethylidenecyclohexane to 1-ethylcyclohexene, ${ }^{12}$ which shows that there are considerable destabilizing interactions between the exo-cyclic methyl group and ring hydrogens in ethylidenecyclohexane. As the methyl group of ethylidenecyclopentane brings about a stabilization of $10.8 \mathrm{~kJ} \mathrm{~mol} \mathrm{~mol}^{-1}$ relative to methylenecyclopentane, the strain between the methyl group and ring hydrogens of ethylidenecyclohexane is about $10.8-5.0=5.8 \mathrm{~kJ} \mathrm{~mol}^{-1}$. This is somewhat higher than the strain in $(Z)$-2-butene, $4.2-4.5$ kJ mol $^{-1},{ }^{14}$ but Skinner ${ }^{1}$ has pointed out that for compounds like 2-methyl-2-butene (and, by analogy, ethylidenecyclohexane) carrying two alkyl groups on one of the two $s p^{2}$-hybridized carbon atoms and one alkyl group on the other, steric crowding is enhanced so that the total strain between the three alkyl groups amounts to $c a .5 .8 \mathrm{~kJ} \mathrm{~mol}^{-1}$, or exactly the same that was found to exist between the methyl group and ring hydrogens of ethylidenecyclohexane. This strain is released when the cis interaction is absent, as in ethylidenecyclopentane and the other small-ring compounds.

Moreover, it can be deduced by means of molecular models that the strain between the methyl group and ring hydrogens of ethylidenecycloalkanes larger than ethylidenecyclohexane should be close to that in ethylidenecyclohexane.

Applied to the present compounds, in addi- tion to the disappearance of the destabilizing interaction between the exo-cyclic methyl group and ring hydrogens on going from 1-methoxy. ethylidenecyclohexane (IVb) to IIIb, IIb, and $\mathrm{Ib}$, there remains the question of the possible change in the interaction energy between the methoxy group and ring hydrogens in the same process. This problem can be solved as follows. From available data, the values of $\Delta H^{\circ}{ }_{f}(1$, $298.15 \mathrm{~K}$ ) of vinylcyclopentane and ethylidenecyclopentane are -34.8 and $-56.7 \mathrm{~kJ} \mathrm{~mol}^{-1}$, respectively. The normal boiling points of the above compounds are 373.5 and $385.8 \mathrm{~K}$, respectively. ${ }^{15}$ Thus the standard enthalpy of vaporization at $298.15 \mathrm{~K}$ of vinylcyclopentane is calculated ${ }^{6}$ to be about 36.7 and that of ethylidenecyclopentane $38.7 \mathrm{~kJ} \mathrm{~mol}{ }^{-1}$. Hence the values of $\Delta H^{\circ}(\mathrm{g}, 298.15 \mathrm{~K})$ of the above compounds are calculated to be about 1.9 and $-18.0 \mathrm{~kJ} \mathrm{~mol}{ }^{-1}$, respectively. Similarly, for vinylcyclohexane and ethylidenecyclohexane, the values of $\Delta H^{\circ}{ }_{f}(1,298.15 \mathrm{~K})$ are -88.7 and $-103.5 \mathrm{~kJ} \mathrm{~mol}^{-1}$, respectively. The normal boiling points of vinylcyclohexane ${ }^{15}(400.2 \mathrm{~K})$ and ethylidenecyclohexane ${ }^{15}(410.0 \mathrm{~K})$ lead to the standard enthalpies of vaporization at $298.15 \mathrm{~K}$ of 41.0 and $42.6 \mathrm{~kJ} \mathrm{~mol}^{-1}$, respectively. Hence the values of $\Delta H^{\circ}(\mathrm{g}, 298.15 \mathrm{~K})$ of vinylcyclohexane and ethylidenecyclohexane are ca. -47.7 and $-60.9 \mathrm{~kJ} \mathrm{~mol}^{-1}$, respectively. Now the following standard enthalpies of isomeriza. tion can be written:

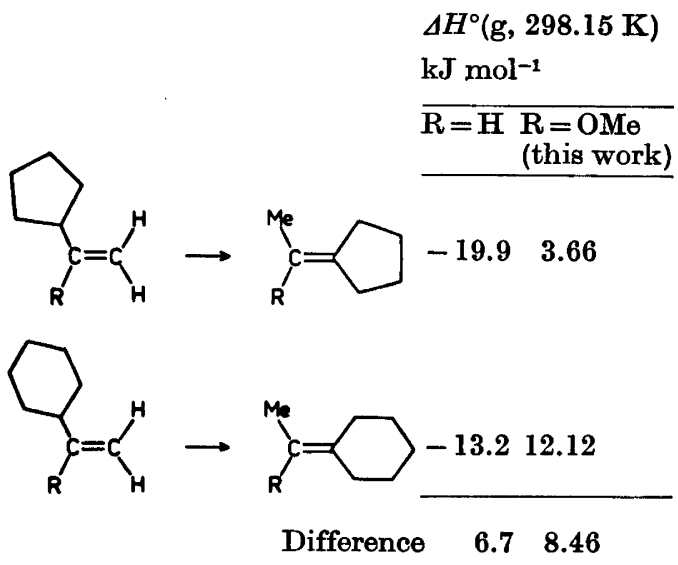

The difference $\Delta H^{\circ}$ (6-membered ring $)-\Delta H^{\circ}(5$ membered ring) is ca. $1.8 \mathrm{~kJ} \mathrm{~mol}^{-1}$ more positive in the case $R=O M e$. Hence the destabilizing

Acta Chem. Scand. B 28 (1974) No. 3 
interaction energy between the methoxy group and ring hydrogens increases slightly on going from the 5-membered to the 6-membered ring compound.

To summarize, the following discussion of ring strain energies is based on three assumptions: (i) in the 6-, 7-, and 8-membered ring compounds $\mathrm{IVb}, \mathrm{Vb}$, and $\mathrm{VIb}$, the strain between the exo-cyclic substituents ( $\mathrm{Me}$ and $\mathrm{MeO}$ ) and ring hydrogens is taken to be equal to that in the reference compound $\mathrm{Rb}$, (ii) this strain (fixed at $5.8+1.8=7.6 \mathrm{~kJ} \mathrm{~mol}^{-1}$ ) is absent in the 3-, 4-, and 5-membered compounds Ib, IIb, and IIIb, and, (iii) the strain in the a isomers (excluding the strain of the saturated ring) is equal to that in the reference compound Ra.

As to the values of $\Delta H^{\circ}(\mathrm{g}, 298.15 \mathrm{~K})$ and $\Delta S^{\circ}(\mathrm{g}, 298.15 \mathrm{~K})$ for the reference reaction, the liquid phase data given in Ref. 11 lead to the following values for the thermodynamic functions in question, if the standard enthalpies and standard entropies of vaporization at $298.15 \mathrm{~K}$ are estimated from the appropriate equations given in Ref. 6: $\Delta H^{\circ}(\mathrm{g}, 298.15 \mathrm{~K})=9.46 \pm 0.40$ $\mathrm{kJ} \mathrm{mol}^{-1}, \Delta S^{\circ}(\mathrm{g}, 298.15 \mathrm{~K})=17.9 \pm 0.9 \mathrm{~J} \mathrm{~K}^{-1}$ $\mathrm{mol}^{-1}$.

Relative ring strain energies. Three-membered ring compounds. In this case only a qualitative result was achieved since the peak of $\mathrm{Ib}$ could not be detected by GLC, owing to the low thermodynamic stability of the three-membered ring with an $s p^{2}$-hybridized carbon atom. Hence the following discussion is based on literature data. From available data, the value of $\Delta H^{\circ}$ (g, 298.15 K) of methylenecyclopropane is found to be ca. $175 \mathrm{~kJ} \mathrm{~mol}^{-1}$ higher than that of a strain-free methylenecyclopropane molecule calculated from the group increments given by Cox and Pilcher." On the other hand, the experimental enthalpy of formation of gaseous cyclopropane ${ }^{4}$ is $115 \mathrm{~kJ} \mathrm{~mol}^{-1}$ higher than the calculated value. Hence the introduction of an $s p^{2}$-hybridized carbon atom into the threemembered saturated ring leads to an increase of ring strain of $c a .60 \mathrm{~kJ} \mathrm{~mol}-\mathbf{1}$, which causes Ib to be highly unfavored at equilibrium.

Four-membered ring compounds. The enthalpy change $\Delta H^{\circ}(\mathrm{g}, 298.15 \mathrm{~K})$ for the reaction 1 methoxyvinylcyclobutane $\rightarrow$ 1-methoxyethyl. idenecyclobutane is $1.96 \mathrm{~kJ} \mathrm{~mol}{ }^{-1}$ more positive than that for $\mathbf{R a} \rightarrow \mathrm{Rb}$. If the correction term of $7.6 \mathrm{~kJ} \mathrm{~mol}^{-1}$ (due to the absence of steric in- teractions across the double bond in IIb) is taken into account, the introduction of an $s p^{2}$. hybridized carbon atom into the cyclobutane ring is seen to increase the ring strain by $1.96+$ $+7.6 \simeq 9.6 \mathrm{~kJ} \mathrm{~mol}^{-1}$. This may be compared with the value obtainable from literature data as follows. The experimental enthalpy of formation of gaseous cyclobutane ${ }^{4}$ and the group increments of Cox and Pilcher lead to a strain energy of ca. $111 \mathrm{~kJ} \mathrm{~mol}^{-1}$ for the cyclobutane ring. The enthalpy of formation of methylenecyclobutane has not been determined experimentally but it can be estimated as follows. The enthalpy of hydrogenation data by Turner and Garner ${ }^{12}$ reveal that the enthalpy of 1 . methylcyclobutene is ca. $3.8 \mathrm{~kJ} \mathrm{~mol} \mathrm{~m}^{-1}$ lower than that of methylenecyclobutane in acetic acid at $298.15 \mathrm{~K}$. Methylenecyclobutane is reported to boil ca. $5 \mathrm{~K}$ higher than 1-methylcyclobutene, ${ }^{16,17}$ and thus the standard enthalpy of vaporization (at $298.15 \mathrm{~K}$ ) of the latter should be about $0.80 \mathrm{~kJ} \mathrm{~mol}^{-1}$ lower than that of the former. ${ }^{6}$ Accordingly, the standard enthalpy change in the reaction methylenecyclobutane $\rightarrow$ 1-methylcyclobutene is about $-4.6 \mathrm{~kJ} \mathrm{~mol}^{-1}$ in the gas phase at $298.15 \mathrm{~K}$, if it is assumed that both isomers have equal enthalpies of solution in acetic acid. The standard enthalpy of formation in the gas phase at $298.15 \mathrm{~K}$ of 1-methylcyclobutene can be estimated by assuming that the difference in the values of $\Delta H^{\circ}{ }_{\mathrm{f}}(\mathrm{g}, 298.15 \mathrm{~K})$ between 1-methylcyclobutene and cyclobutene is equal to that between 1-methylcyclopentene and cyclopentene. The value of $\Delta H^{\circ}{ }_{\mathrm{f}}(1,298.15 \mathrm{~K})$ of 1-methylcyclopentene is $-36.2 \mathrm{~kJ} \mathrm{~mol}^{-1}$, $^{4}$ and as the normal boiling point ${ }^{10}$ (348.7 K) corresponds to a standard enthalpy of vaporization of $32.7 \mathrm{~kJ} \mathrm{~mol}^{-1}$ at $298.15 \mathrm{~K},{ }^{6}$ the value of $\Delta H^{\circ}(\mathrm{g}, 298.15 \mathrm{~K})$ of 1-methylcyclopentene is obtained as $-3.5 \mathrm{~kJ} \mathrm{~mol}^{-1}$. As the corresponding value for cyclopentene is $32.4 \mathrm{~kJ}$ $\mathrm{mol}^{-1}{ }^{4}$ the difference in the values of $\Delta H_{\mathrm{f}}^{\circ} \mathrm{g}$, 298.15 K) between cyclopentene and 1-methylcyclopentene is about $35.9 \mathrm{~kJ} \mathrm{~mol}^{-1}$. For cyclobutene, $\Delta H^{\circ}{ }_{\mathrm{f}}(\mathrm{g}, 298.15 \mathrm{~K})$ is ca. $156.7 \mathrm{~kJ} \mathrm{~mol}^{-1}$, $^{4}$ which leads to a $\Delta H^{\circ}(\mathrm{g}, 298.15 \mathrm{~K})$ of $156.7-$ $35.9=120.8 \mathrm{~kJ} \mathrm{~mol}^{-1}$ for 1-methylcyclobutene. Hence the standard enthalpy of formation of gaseous methylenecyclobutane is calculated to be $120.8+4.6=125.4 \mathrm{~kJ} \mathrm{~mol}^{-1}$ at $298.15 \mathrm{~K}$. The group increments suggest a standard enthalpy of formation of $5.1 \mathrm{~kJ} \mathrm{~mol}^{-1}$ for a strain-free

Acta Chem. Scand. B 28 (1974) No. 3 
methylenecyclobutane, and thus the strain in methylenecyclobutane is obtained as $120 \mathrm{~kJ}$ $\mathrm{mol}^{-1}$, which is $9 \mathrm{~kJ} \mathrm{~mol}^{-1}$ higher than the strain in cyclobutane. The result achieved is practically equal to that obtained in this study.

Five-membered ring compounds. If the correction term of $7.6 \mathrm{~kJ} \mathrm{~mol}^{-1}$ is added to the difference $\left(-5.80 \mathrm{~kJ} \mathrm{~mol}^{-1}\right.$ ) between the gas phase standard enthalpies of isomerization of 1 methoxyvinylcyclopentane (IIIa) to 1-methoxyethylidenecyclopentane (IIIb) and Ra to Rb, the introduction of an $s p^{2}$-hybridized carbon atom into the cyclopentane ring is seen to cause a slight increase $\left(1.8 \mathrm{~kJ} \mathrm{~mol}^{-1}\right)$ in ring strain energy. This result is in good agreement with the value obtainable from literature data. The standard enthalpy of formation of liquid methylenecyclopentane is $-20.1 \mathrm{~kJ} \mathrm{~mol}^{-1}$ at $298.15 \mathrm{~K}$, and the standard enthalpy of vaporization at $298.15 \mathrm{~K}$ is estimated to be $c a$. $32.7 \mathrm{~kJ} \mathrm{~mol}^{-1}$ (normal boiling point $348.8 \mathrm{~K}^{15}$ ) leading to a $\Delta H^{\circ}{ }_{\mathrm{f}}(\mathrm{g}, 298.15 \mathrm{~K})$ of $12.6 \mathrm{~kJ} \mathrm{~mol}^{-1}$, which is $28.1 \mathrm{~kJ} \mathrm{~mol}^{-1}$ more positive than the value $-15.5 \mathrm{~kJ} \mathrm{~mol}^{-1}$, calculated by means of the group increments. On the other hand, the strain in cyclopentane is obtained to be $25.8 \mathrm{~kJ}$ $\mathrm{mol}^{-1}$ from its experimental ${ }^{4}$ and estimated enthalpy of formation. Thus the literature data lead to an increase of $c a .2 \mathrm{~kJ} \mathrm{~mol}^{-1}$ in ring strain energy on going from cyclopentane to methylenecyclopentane.

Six-membered ring compounds. The enthalpy of isomerization of 1-methoxyvinylcyclohexane (IVa) to I-methoxyethylidenecyclohexane (IVb) is $2.66 \mathrm{~kJ} \mathrm{~mol}^{-1}$ more positive than that of $\mathrm{Ra}$ to $\mathrm{Rb}$ showing that the introduction of an $s p^{2}$ hybridized carbon atom into the saturated sixmembered ring increases the strain by this amount. The data of Turner and Garner ${ }^{12}$ show that the enthalpy of methylenecyclohexane is ca. $10.0 \mathrm{~kJ} \mathrm{~mol}^{-1}$ higher than that of 1-methylcyclohexene in acetic acid at $298.15 \mathrm{~K}$. The value of $\Delta H^{\circ}{ }_{f}(1,298.15 \mathrm{~K})$ of 1-methylcyclohexene is about $-81.2 \mathrm{~kJ} \mathrm{~mol}^{-1}, 4$ and thus the standard enthalpy of formation of liquid methylenecyclohexane is about $-71.2 \mathrm{~kJ} \mathrm{~mol}^{-1}$ at $298.15 \mathrm{~K}$. The normal boiling point of methylenecyclohexane is $376.5 \mathrm{~K}^{16}$ corresponding to a standard enthalpy of vaporization at $298.15 \mathrm{~K}$ of about $37.2 \mathrm{~kJ} \mathrm{~mol}^{-1}$, and hence the value of $\Delta H^{\circ}{ }_{\mathrm{f}}(\mathrm{g}, 298.15 \mathrm{~K})$ of methylenecyclohexane is ca. $-34.0 \mathrm{~kJ} \mathrm{~mol}{ }^{-1}$. The group increments suggest a $\Delta H^{\circ}(\mathrm{g}, 298.15 \mathrm{~K})$ of $-36.1 \mathrm{~kJ} \mathrm{~mol}^{-1}$ for a strain-free methylenecyclohexane. Thus the strain in this compound is about $2 \mathrm{~kJ} \mathrm{~mol}^{-1}$. From the experimental enthalpy of formation of gaseous cyclohexane " the strain of the saturated six-membered ring is calculated to be about $0 \mathrm{~kJ} \mathrm{~mol}^{-1}$ which is $2 \mathrm{~kJ} \mathrm{~mol}^{-1}$ less than the strain in methylenecyclohexane. This result is in reasonable agreement with the value $2.7 \mathrm{~kJ}$ $\mathrm{mol}^{-1}$ achieved in this study.

Seven-membered ring compounds. The enthalpy of isomerization of 1-methoxyvinylcycloheptane (Va) to 1-methoxyethylidenecycloheptane (Vb) is $1.73 \mathrm{~kJ} \mathrm{~mol}^{-1}$ while that of $\mathrm{Ra}$ to $\mathrm{Rb}$ is 9.46 $\mathrm{kJ} \mathrm{mol}^{-1}$. Hence the seven-membered ring containing an $s p^{2}$-hybridized carbon atom is about $7.7 \mathrm{~kJ} \mathrm{~mol}^{-1}$ less strained than the saturated ring. From enthalpy of hydrogenation measurements, ${ }^{12}$ the enthalpy of isomerization of methylenecycloheptane to 1-methylcycloheptene is ca. $-9.6 \mathrm{~kJ} \mathrm{~mol}^{-1}$ in acetic acid at $298.15 \mathrm{~K}$. As the normal boiling point of the former is about $1 \mathrm{~K}$ lower than that of the latter, ${ }^{12}$ the enthalpy difference is about $\mathbf{- 9 . 4}$ $\mathrm{kJ} \mathrm{mol} \mathrm{m}^{-1}$ in the gas phase. Moreover, if it is assumed that the difference in the values of $\Delta H^{\circ}{ }^{\circ}(\mathrm{g}, \quad 298.15 \mathrm{~K})$ between cycloheptene $\left[\Delta H_{\mathrm{f}}^{\circ}(\mathrm{g}, 298.15 \mathrm{~K})=-9.2 \mathrm{~kJ} \mathrm{~mol}{ }^{-1}\right.$, Ref. 4] and 1-methylcycloheptene is the same as the corresponding difference between cyclohexene and I-methylcyclohexene, $38.7 \mathrm{~kJ} \mathrm{~mol}^{-1}$, the value of $\Delta H_{\mathrm{f}}^{\circ}(\mathrm{g}, 298.15 \mathrm{~K})$ for 1-methylcycloheptene is obtained as $-9.2-38.7=-47.9 \mathrm{~kJ} \mathrm{~mol}{ }^{-1}$. Hence for methylenecycloheptane, $\Delta H_{\mathrm{f}}^{\circ}(\mathrm{g}$, $298.15 \mathrm{~K})=-47.9+9.6=-38.3 \mathrm{~kJ} \mathrm{~mol}^{-1}$, which is $c a .18 \mathrm{~kJ} \mathrm{~mol}^{-1}$ more positive than the value $-56.7 \mathrm{~kJ} \mathrm{~mol}^{-1}$ calculated from the group increments. On the other hand, the experimental standard enthalpy of formation of gaseous cycloheptane ${ }^{4}$ is $26 \mathrm{~kJ} \mathrm{~mol}^{-1}$ more positive than the calculated value. Thus the decrease in ring strain energy on going from cycloheptane to methylenecycloheptane is about $8 \mathrm{~kJ} \mathrm{~mol}^{-1}$, in agreement with the result $(7.7 \mathrm{~kJ}$ mol $^{-1}$ ) obtained in this study.

Eight-membered ring compounds. The results of the present work indicate that the introduction of an $s p^{2}$-hybridized carbon atom into cyclooctane decreases the ring strain energy by $9.46-(-3.41) \simeq 12.9 \mathrm{~kJ} \mathrm{~mol}^{-1}$. In the absence of suitable literature data, a comparison cannot be made.

Acta Chem. Scand. B 28 (1974) No. 3 
Summary of the changes of ring strain energy. From the above discussion it appears that on going from a cycloalkane to the corresponding alkylidenecycloalkane, the values of ring strain energy undergo the following changes:

$\begin{array}{lc}\text { Ring size } & \begin{array}{l}\text { Increase of ring strain } \\ \text { energy } / \mathrm{kJ} \mathrm{mol}^{-1}\end{array} \\ \mathrm{C}_{3} & 60 \text { from literature data } \\ \mathrm{C}_{4} & 9.6 \\ \mathrm{C}_{5} & 1.8 \\ \mathrm{C}_{6} & 2.7 \\ \mathrm{C}_{7} & -7.7 \\ \mathrm{C}_{8} & -12.9\end{array}$

These results have been combined with some literature data in Table 6, which shows the values of ring strain energy in carbocyclic rings with no, one, or two $s p^{2}$-hybridized carbon atoms. The literature data are based on the difference between the experimental ${ }^{4}$ and estimated standard enthalpies of formation of the gaseous compounds at $298.15 \mathrm{~K}$.

The increase of ring strain energy in the three- and four-membered rings with increasing unsaturation of the ring carbons is undoubtedly due to increased bending of the carbon-carbon bond angles from their normal values. On the other hand, the decrease of ring strain in the large-ring compounds $\left(\mathrm{C}_{7}\right.$ and $\left.\mathrm{C}_{8}\right)$ in the same sequence points to decreased destabilizing interactions between incompletely staggered adjacent bonds, or/and to decreased transannular interactions (see, for example, Ref. 18).

Relative ring entropies. For each isomeriza-

Table 6. Values of ring strain energy (in $\mathrm{kJ}$ $\mathrm{mol}^{-1}$ ) in some saturated and unsaturated carbocyclic rings.

\begin{tabular}{lccc}
\hline $\begin{array}{l}\text { Ring } \\
\text { size }\end{array}$ & \multicolumn{3}{c}{$\begin{array}{l}\text { Ring strain energy in } \\
\text { cycloalkane } \\
\text { alkylidene- } \\
\text { cycloalkane }\end{array}$} \\
\hline \multicolumn{4}{c}{ cycloalkene } \\
\hline $\mathrm{C}_{3}$ & 115 & 175 & 225 \\
$\mathrm{C}_{4}$ & 111 & 120 & 126 \\
$\mathrm{C}_{5}$ & 26 & 28 & 24 \\
$\mathrm{C}_{8}$ & 0 & 3 & 5 \\
$\mathrm{C}_{8}$ & 26 & 18 & 21 \\
$\mathrm{C}_{8}$ & 40 & 27 & 24 \\
\hline
\end{tabular}

Acta Chem. Scand. B 28 (1974) No. 3 tion reaction studied in this work, the value of $\Delta S^{\circ}(\mathrm{g}, 298.15 \mathrm{~K})$ is less positive than the entropy change in the reference reaction. As the differences in the values of $\Delta S^{\circ}$ for the reference reaction and the $a \rightarrow b$ reactions must be due to differences in ring entropy between a saturated carbocyclic ring and the corresponding ring containing an $s p^{2}$-hybridized carbon atom the entropy data show that the saturated ring has a greater entropy value. This result is in agreement with the decreasing values of intrinsic entropy ${ }^{7,19}$ on going from cycloalkanes to cycloalkenes or to more highly unsaturated cyclic olefins. O'Neal and Benson ${ }^{19}$ have described a method for estimating gas phase entropies of carbocyclic compounds with one or more endo-cyclic double bonds from the entropies of the corresponding cycloalkanes by making certain corrections the most important of which is the "double bond tightness correction". This correction is negative for cycloalkenes up to cyclooctene except for cyclo. propene for which it is zero. It is of interest to compare the value of the "endo-cyclic double bond tightness corrections" of O'Neal and Benson with the "exo-cyclic double bond tightness corrections" obtainable from this study by subtracting $17.9 \mathrm{~J} \mathrm{~K}^{-1} \mathrm{~mol}^{-1}$ (the value of $\Delta S^{\circ}$ for the reference reaction) from the entropy changes in the $a-b$ reactions involving fourto eight-membered carbocyclic rings:

\section{Ring size}

Exo-cyclic vs. endo-cyclic double bond tightness correction $/ \mathrm{J} \mathrm{K}^{-1} \mathrm{~mol}^{-1}$

$\begin{array}{ll}\mathrm{C}_{4} & -6.0 /-7.9 \\ \mathrm{C}_{5} & -8.9 /-16.3 \\ \mathrm{C}_{6} & -0.8 / 0.0 \\ \mathrm{C}_{7} & -6.2 /-10.4 \\ \mathrm{C}_{8} & -7.6 /-13.4\end{array}$

The negative values of the double bond tightness corrections show that in general, increasing unsaturation of the ring carbons leads to increased rigidity of the ring. This effect is least marked for the six-membered ring; on the other hand, it attains a maximum value for the five-membered ring. Hence, on going from cyclohexane to methylenecyclohexane, the rigidity of the ring undergoes only a slight increase. This is understandable since methylene- 
cyclohexane exists in a chair conformation, ${ }^{90}$ and thus there is no change in conformation on going from cyclohexane to methylenecyclohexane. However, on going from cyclopentane to methylenecyclopentane, the flexible envelope conformation of cyclopentane is changed to a more rigid half-chair conformation in methylenecyclopentane. ${ }^{18}$

As an application of the exo-cyclic double bond tightness corrections given above, the entropy change $\Delta S^{\circ}(\mathrm{g}, 298.15 \mathrm{~K})$ for the reaction methylenecyclopentane $\rightarrow$ 1-methylcyclopentene is estimated by means of the group increment method proposed by Benson et al. ${ }^{7}$ For cyclic compounds, a ring correction term is necessary. This is obtained as $105.3 \mathrm{~J} \mathrm{~K}^{-1} \mathrm{~mol}^{-1}$ for the five-membered ring in methylenecyclopentane by summing the ring correction term for a saturated five-membered carbocyclic ring (114.2 $\mathrm{J} \mathrm{K}^{-1} \mathrm{~mol}^{-1}$ ) given by Benson et al., and the exo-cyclic double bond tightness correction term $\left(-8.9 \mathrm{~J} \mathrm{~K}^{-1} \mathrm{~mol}^{-1}\right)$ for a five-membered ring. Now the entropies $S^{\circ}(\mathrm{g}, 298.15 \mathrm{~K})$ of methylenecyclopentane (symmetry number $=2$ ) and 1-methylcyclopentene (external symmetry number $=1$ ) are estimated to be 322.9 and 327.7 $\mathrm{J} \mathrm{K}^{-1} \mathrm{~mol}^{-1}$, respectively. Hence the entropy change for the reaction in question is calculated to be about $4.8 \mathrm{~J} \mathrm{~K}^{-1} \mathrm{~mol}^{-1}$. From equilibrium ${ }^{21}$ and enthalpy of hydrogenation ${ }^{12}$ studies in acetic acid at $298.15 \mathrm{~K}$, the values of $\Delta G^{\circ}$ and $\Delta H^{\circ}$ are -17.45 and $-16.2 \mathrm{~kJ} \mathrm{~mol}^{-1}$, respectively, and hence the standard entropy change $\Delta S^{\circ}(1,298.15 \mathrm{~K})$ is obtained as $4.2 \mathrm{~J} \mathrm{~K}^{-1} \mathrm{~mol}^{-1}$. Since the normal boiling points of the compounds in question are equal within $1 \mathrm{~K},,^{15,22}$ they are expected to have practically equal standard entropies of vaporization at $298.15 \mathrm{~K}$, and hence the value of $\Delta S^{\circ}(\mathrm{g}, 298.15 \mathrm{~K})$ is ca. 4.2 $\mathrm{J} \mathrm{K}^{-1} \mathrm{~mol}^{-1}$, in agreement with the estimated value.

\section{REFERENCES}

1. Skinner, H. A. J. Chem. Soc. (1962) 4396.

2. Schleyer, P. v. R., Williams, J. E. and Blanchard, K. R. J. Amer. Chem. Soc. 92 (1970) 2377.

3 Allinger, N. L. and Sprague, J. T. J. Amer. Chem. Soc. 94 (1972) 5734.

4. Cox, J. D. and Pilcher, G. Thermochemistry of Organic and Organometallic Compounds, Academic, London and New York 1970.
5. Wiberg, K. B. and Fenoglio, R. A. J. Amer. Chem. Soc. 90 (1968) 3395.

6. Taskinen, E. J. Chem. Thermodyn. 6 (1974) 271.

7. Benson, S. W., Cruickshank, F. R., Golden, D. M., Haugen, G. R., O'Neal, H. E., Rodgers, A. S., Shaw, R. and Walsh, R. Chem. Rev. 69 (1969) 279.

8. Mortimer, C. T. Reaction Heats and Bond Strengths, Pergamon, Oxford 1962, Chapter 3.

9. House, H. O. and Kramar, V. J. Org. Chem. 28 (1963) 3362.

10. Brown, H. C. and Garg, C. P. J. Amer. Chem. Soc. 83 (1961) 2952.

11. Taskinen, E. J. Chem. Thermodyn. 5 (1973) 783.

12. Turner, R. B. and Garner, R. H. J. Amer. Chem. Soc. 80 (1958) 1424.

13. Bigley, D. B. and May, R. W. J. Chem. Soc. $B$ (1970) 1761 .

14. Meyer, E. F. and Strotz, D. G. J. Amer. Chem. Soc. 94 (1972) 6344.

15. van der Bij, J. R. and Kooyman, E. C. Rec. Trav. Chim. Pays-Bas 71 (1952) 837.

16. Slabey, V. A. J. Amer. Chem. Soc. 68 (1946) 1335.

17. Shand, Jr., W., Schomaker, V. and Fischer, J. R. J. Amer. Chem. Soc. 66 (1944) 636.

18. McQuillin, F. J. Alicyclic Chemistry, Cambridge University Press, London 1972, Chapter 2.

19. O'Neal, H. E. and Benson, S. W. J. Chem. Eng. Data 15 (1970) 266.

20. Gerig, J. T. and Rimerman, R. A. J. Amer. Chem. Soc. 92 (1970) 1219.

21. Cope, A. C., Ambros, D., Ciganek, E., Howell, C. F. and Jacura, Z. J. Amer. Chem. Soc. 82 (1960) 1750.

22. Sperling, R. J. Chem. Soc. (1949) 1925.

Received November 14, 1973. 